\title{
Efektivitas Penggunaan UKBM Terhadap Literasi Sains Materi Alat Optik Dalam Model PjB-STEM Dengan Asesmen Formatif Pada Siswa Kelas XI MIA SMA Negeri 9 Malang
}

\author{
${ }^{1}$ Choirun Nisah Alifiyah, ${ }^{2}$ Parno, ${ }^{3}$ Sentot Kusairi \\ ${ }^{1}$ Mahasiswa Program Studi Pendidikan Fisika, Universitas Negeri Malang, \\ ${ }^{2}$ Dosen Jurusan Fisika, Universitas Negeri Malang, Indonesia \\ Email: ${ }^{1}$ choirunnisahalifiyah4@gmail.com, ${ }^{2}$ parno.fmipa@um.ac.id, \\ ${ }^{3}$ sentot.kusairi.fmipa@um.ac.id
}

\begin{tabular}{l}
\hline Tersedia Online di \\
\hline http://www.jurnal.unublitar.ac.id/ \\
index.php/briliant \\
\hline \\
\hline Sejarah Artikel \\
\hline Diterima pada 15 Juli 2020 \\
Disetujui pada 20 November \\
2020 \\
Dipublikasikan pada 30 \\
November 2020 \\
Hal. 679-686 \\
\hline Kata Kunci: \\
\hline UKBM, PjBL-STEM; \\
Formative Assessment; Science \\
Literacy \\
\hline DOI: \\
\hline http://dx.doi.org/10.28926/briliant \\
.v3i4.515
\end{tabular}

\section{Tersedia Online di}

http://www.jurnal.unublitar.ac.id/

\begin{abstract}
Abstrak: Penelitian ini bertujuan untuk menguji efektivitas penggunaan UKBM berbasis PjBLSTEM terhadap literasi sains materi alat optik dalam model PjBL-STEM dengan asesmen formatif pada siswa kelas XI MIA SMA Negeri 9 Malang. Jenis rancanngan penelitian yang digunakan yaitu quasi experiment dengan desain penelitian pretest-posttest control group design. Kemampuan literasi sains peserta didik sebagai variabel terikat yang menjadi tolak ukur dalam penelitian ini. Berdasarkan hasil analisis data dari uji hipotesis diperoleh $t_{\text {hitung }}>t_{\text {tabel }}=6,890>1,67$ dengan taraf signifikansi 0,05 maka $\mathrm{H}_{0}$ ditolak dan $\mathrm{H}_{1}$ diterima. Dengan demikian, dapat disimpulkan bahwa siswa kelas XI MIA SMA Negeri 9 Malang pada pokok bahasan alat optik yang diberi perlakuan menggunakan UKBM berbasis $\mathrm{PjBL}$ STEM dalam model PjBL-STEM dengan asesmen formatif memiliki peningkatan literasi sains lebih tinggi dibandingkan dengan yang diberi perlakuan menggunakan model PjBL-STEM dengan asesmen formatif.
\end{abstract}

\section{PENDAHULUAN}

Materi alat optik seperti yang tertera pada kurikulum 2013 berdasarkan KI dan KD yaitu mendeskripsikan cara kerja alat optik menggunakan sifat pencerminan dan pembiasan cahaya oleh cermin dan lensa, serta membuat karya yang menerapkan prinsip pemantulan dan pembiasan pada cermin dan lensa. Untuk mencapai tujuan pembelajaran sesuai dengan KI dan KD diperlukannya perangkat pembelajaran yang mendukung. Bedasarkan penelitian yang dilakukan Hermawan \& Arif (2014) penyebaran angket yang diberikan kepada siswa terkait mata pelajaran fisika yang masih dianggap sulit adalah materi alat optik, hal ini dibuktikan dengan adanya jawaban siswa yang masih banyak salah ketika menyebutkan contoh-contoh alat optik beserta hukum pemantulannya. Permasalahan yang dialami oleh siswa yang disampaikan oleh Elina, dkk (2017) bahwa siswa sulit untuk membedakan antara bayangan maya dengan bayangan nyata yang terjadi pada pembentukan bayangan dari setiap alat optik. Dengan begitu diperlukannya cara untuk menyelesaikan permasalahan tersebut agar sesuai dengan tujuan pembelajaran. 
Menurut Kurnia \& Fathurohman (2014) kemampuan yang dimiliki siswa dalam penguasaan ilmu-ilmu pengetahuan dan sains dalam suatu proses pembelajaran sering diistilahkan sebagai literasi sains. PISA (2015) mendefinisikan bahwa literasi sains merupakan kemampuan yang dimiliki seseorang dengan keterlibatan isu-isu dan ide-ide sains yang digunakan dengan harapan siswa menjadi warga negara yang mampu melihat keadaan sekitar. Jadi menurut (Gherardini, 2016; Kurnia \& Fathurohman, 2014) literasi sains menjadi hal yang sangat penting untuk dikuasai, dikarenakan literasi sains memiliki hubungan yang sangat erat dengan kemampuan siswa dalam memahami lingkungan hidup dan masalah-masalah di lingkungan. Hasil studi PISA 2015, menurut Nurjannah, dkk. (2017) diketahui bahwa kemampuan literasi sains yang dimiliki siswa di Indonesia masih sangat rendah dengan peringkat 69 dari 76 negara dengan score 403.

Menurut penelitian yang dilakukan oleh Asyhari \& Hartati (2015) bahwa hasil pembelajaran yang diberikan kepada siswa dengan menggunakan pendekatan saintifik mampu meningkatkan kemampuan literasi sains siswa dibandingkan menerapkan proses pembelajaran yang tidak menggunakan pendekatan secara saintifik. Rahayuni (2016) menyatakan bahwa pada penelitian yang dilakukan diberlakukannya proses pembelajaran dengan model PBM mengalami kenaikan nilai sebesar 0,82 terhadap literasi sains siswa. Berdasarkan penelitian tersebut dapat dikatakan bahwa diperlukannya proses pembelajaran dengan berbasis masalah outentik. Akan tetapi penelitian yang terkait dengan pembelajaran yang diakukan untuk meningkatkan literasi sains dengan berbasis masalah outentik masih minim dilakukan. Berdasarkan penelitian yang telah dilakukan sebelumnya tidak terdapat peneitian yang menggunakan PjBL-STEM dan asesmen formatif dalam kegiatan pembelajaran untuk meningkatkan literasi sains.

Guru perlu berupaya membangun dan meningkatkan literasi sains siswa dengan mengemas pembelajaran yang mampu meningkatkan literasi sains. Menurut Rahayuni (2016) penggunaan metode dan model pembelajaran menjadi faktor yang mempengaruhi rendahnya literasi sains, dimana hal tersebut sangat bersinggungan dengan proses pembelajaran yang diberikan. Menurut Asyhari \& Hartati (2015) bahwa perangkat pembelajaran yang mampu meningkatkan literasi sains yaitu dengan menggunakan pendekatan scientific. Dengan menggunakan perangkat pembelajan yang mendukung implementasi kurikulum 2013 adalah pendekatan terpadu STEM (Science, Technology, Engineering, and Mathematics).

Menurut Rachmawati \& Gani (2017) bahwa proses pembelajaran fisika menekankan pada pemberian pengalaman langsung untuk mengembangkan kompetensi dengan baik. Model pembelajaran aktif yang dapat mengatasi masalah tersebut dengan menggunakan model pembelajaran Project Based Learning. Pembelajaran dengan menggunakan model PjBL-STEM yaitu pembelajaran yang berbasis proyek dengan mengintegrasikan STEM (Science, Technology, Engineering, and Mathematics) digunakan untuk memecahkan permasalahan (National STEM Education Center, 2014). Penelitian yang dilakukan oleh Rahayuni (2016) diberlakukannya proses pembelajaran berbasis masalah outentik mampu meningkatkan literasi sains.

680 BRILIANT: Jurnal Riset dan Konseptual Volume 5 Nomor 4, November 2020 
Proses pembelajaran dengan menggunakan model PjBL-STEM yang dilakukan disertai asesmen formatif akan memberikan hasil yang lebih baik (Pryor \& Kang, 2013). Asesmen formatif merupakan proses pembelajaran yang dilakukan oleh guru dan siswa dengan memberikan feedback pada proses pembelajaran. Dengan begitu penggunaan model PjBL yang diintegrasikan dengan STEM dengan asesmen formatif mampu meningkatkan literasi sains siswa.

UKBM (Unit Kegiatan Belajar Mandiri) merupakan satuan pelajaran yang disusun dengan kegiatan pembelajaran diri tingkat kesukaran yang rendah menuju tingkat kesukan yang tinggi. Penelitian yang dilakukan oleh Afifah, dkk (2016) pada kelas yang menggunakan buku guru dan siswa terintegrasi literasi sains memperoleh skor rata-rata yang lebih tinggi daripada kelas yang tidak menggunakan buku guru dan siswa. Dengan begitu dibutuhkannya buku ajar fisika yang mampu mencapai indicator secara pengetahuan, penyelidikan, cara berpikir, dan interaksi antara sains, teknologi, dan masyarakat yang dikemas dengan menggunakan UKBM. UKBM ini dikemas dengan berbasis PjBL-STEM yang berarti proses pembelajaran dengan berbasis masalah yang nantinya berupa proyek yang sesuai dengan KD pada materi alat optik dan dalam proses pembelajaran tidak terlepas dari pendekatan STEM. Dalam penerapannya, UKBM ini digunakan oleh peserta didik secara individu, maksudnya dibagikan kepada semua peserta didik dan semua dapat menggunakannya untuk proses pembelajaran untuk memudahkan peserta didik ketika mengikuti pelajaran fisika terutama materi alat optik. Berdasarkan permasalahan diatas, adapun tujuan dari penelitian ini adalah untuk menguji efektivitas penggunaan UKBM berbasis PjBL-STEM terhadap literasi sains materi alat optik dalam model PjBL-STEM dengan asesmen formatif pada siswa kelas XI MIA SMA Negeri 9 Malang.

\section{METODE}

Penelitian ini menggunakan jenis rancangan penelitian eksperimen semu (quasi experiment) dengan desain penelitian pretest-posttest control group design. Variabel yang digunakan dalam penelitian ini adalah variabel bebas, variabel terikat, dan variabel kontrol. Variabel bebas dalam penelitian ini adalah penggunaan UKBM berbasis PjBL - STEM dalam model PjBL-STEM dengan asesmen formatif yang dibelajarkan pada kelas eksperimen, dan model pembelajaran PjBL-STEM dengan asesmen formatif tanpa menggunakan UKBM berbasis PjBL-STEM yang dibelajarkan pada kelas kontrol. Kemampuan literasi sains siswa pada materi alat optik merupakan variabel terikat dalam penelitian ini. Variabel kontrol dalam penelitian ini adalah model pembelajaran yang dibuat sama untuk kelas eksperimen dan kelas kontrol.

Penelitian ini dilaksanakan pada semester genap tahun ajaran 2019/2020 di SMA Negeri 9 Malang. Populasi dalam penelitian ini adalah seluruh pesera didik kelas XI MIA SMAN 9 Malang. Sampel dalam penelitian ini diambil menggunakan teknik cluster random sampling agar setiap kelas dari populasi memiliki kesempatan yang sama untuk menjadi sampel. Sampel dalam penelitian ini adalah kelas XI MIA 2 sebagai kelas eksperimen dan XI MIA 3 sebagai kelas kontrol.

Instrumen yang digunakan dalam penelitian ini terdiri dari dua macam, yaitu instrument perlakuan dan instrument pengukuran. Instrumen perlakuan digunakan untuk memberikan perlakuan selama proses pembelajaran yang berupa berupa 
perangkat pembelajaran, diantaranya Rencana Pelaksanaan Pembelajaran (RPP) dan Unit Kegiatan Belajar Mandiri (UKBM). Dalam penelitian ini, Rencana Pelaksanaan Pembelajaran (RPP) yang digunakan ada dua macam, yaitu RPP untuk pembelajaran dengan menggunakan UKBM dalam model PjBL - STEM dengan asesmen formatif pada kelas eksperimen dan RPP dengan model pembelajaran PjBL-STEM dengan asesmen formatif tanpa menggunakan UKBM pada kelas kontrol. Berdasarkan hasil validitas konstruk didapatkan hasil bahwa pada instrumen RPP disetujui dengan adanya revisi besar. Instrumen butir soal literasi sains siswa disetujui 21 soal dengan beberapa revisi kecil.

Instrumen pengukuran merupakan perangkat penelitian yang mengukur literasi sains peserta didik. Instrumen pengukuran yang digunakan berupa lembar observasi, soal pretest, dan soal posttest. Sebelum istrumen soal digunakan dalam penelitian, soal tersebut diuji validitasnya, kemudian dilakukan uji coba pada kelas yang bukan merupakan sampel penelitian. Berdasarkan data yang didapatkan dari hasil uji coba pada siswa kelas XII MIPA di SMA Negeri 9 Malang sebanyak 84 siswa diperoleh hasil bahwa 19 butir soal dari 21 soal yang diujikan masuk pada kategori valid dan layak digunakan. Soal-soal yang telah valid digunakan untuk sebagai soal pretest dan soal posttest kelas eksperimen dan kelas kontrol. Setelah dilakukan uji coba, butir soal diuji reliabilitas dan daya pembedanya. Berdasarkan hasil uji reliabilitas soal yang akan digunakan untuk pretest-posttest kelas eksperimen dan kelas kontrol diperoleh hasil bahwa 19 soal tersebut memiliki reliabilitas yang sangat tinggi dengan koefisien reliabilitas sebesar 0,87 .

Teknik pengumpulan data dalam penelitian ini dilakukan dengan observasi, dan tes. Observasi dilakukan untuk mengamati kegiatan pembelajaran di kelas eksperimen dan kelas kontrol selama kegiatan pembelajaran berlangsung. Kemudian tes dilakukan selama dua kali yaitu pretest dan posttest untuk mengetahui peningkatan kemampuan literasi sains siswa. Pretest - Posttest dilakukan pada kelas eksperimen dan kelas kontrol sebelum dan sesudah diberikan perlakuan.

Teknik analisis data yang digunakan dalam penelitian ini adalah teknik analisis deskripti kuantitatif, yakni untuk mengetahui ada atau tidaknya peningkatan kemampuan literasi sains antara kelas eksperimen yang dibelajarkan menggunakan UKBM berbasis PjBL - STEM dalam model PjBL-STEM dengan asesmen formatif dengan kelas kontrol yang dibelajarkan tanpa menggunakan UKBM berbasis PjBL-STEM dalam model PjBL-STEM dengan asesmen formatif. Dalam penelitian ini, data yang terkumpul diantaranya nilai pretest untuk mengetahui kesamaan rata-rata antara kedua kelas dan nilai posttest untuk selanjutnya dilakukan analisis data dengan menggunakan uji kesamaan rata-rata dan uji hipotesis. Pada tahapan uji kesamaan rata-rata dilakukan teknik uji-t dengan prasyarat sampel yang dipakai harus terdistribusi normal dan homongen.

\section{HASIL}

Berdasarkan hasil uji prasyarat analisis terhadap data pretest dan pretestposttest kemampuan literasi sains siswa pada kelas eksperimen dan kelas kontrol, didapatkan bahwa semua data pretest dan pretest-posttest terdistribusi normal dan homogen. Adapun hasil pretest dan pretest-posttest kemampuan literasi sains siswa kelas eksperimen dan kelas kontrol dapat dilihat pada Tabel 1 dan Tabel 2.

682 BRILIANT: Jurnal Riset dan Konseptual

Volume 5 Nomor 4, November 2020 
Tabel 1. Hasil Pretest Kels Eksperimen dan Kelas Kontrol

\begin{tabular}{lcc}
\hline Statistik & Eksperimen & Kontrol \\
\hline Jumlah & 30 & 34 \\
\hline Rata-Rata & 12,8 & 25,9 \\
\hline SD & 6,2 & 3,9 \\
\hline Varians & 38,234 & 15,416 \\
\hline
\end{tabular}

Tabel 2. Hasil Peningkatan pretest-posttest Kels Eksperimen dan Kelas

Kontrol

\begin{tabular}{lcc}
\hline Statistik & Eksperimen & Kontrol \\
\hline Jumlah & 30 & 34 \\
\hline Rata-Rata & 34,633 & 22,529 \\
\hline SD & 8,616 & 5,212 \\
\hline Varians & 74,240 & 27,166 \\
\hline
\end{tabular}

Pada Tabel 1, terlihat bahwa hasil pretest kelas eksperimen dan kelas kontrol adalah berbeda. Pada Tabel 2, terlihat bahwa hasil peningkatan pretestposttest kelas eksperimen lebih tinggi dibandingkan kelas kontrol. Berdasarkan hasil uji keasamaan keadaan awal pretest kelas eksperimen dan kelas kontrol menunjukkan bahwa keadaan awal sebelum pembelajaran kelas eksperimen dan kelas kontrol berbeda. Dengan kata lain, terdapat perbedaan kemampuan literasi sains siswa yang akan diajarkan dengan menggunakan UKBM berbasis PjBLSTEM dalam model PjBL-STEM dengan asesmen formatif dan yang akan diajarkan tanpa menggunakan UKBM berbasis PjBL-STEM dalam model PjBLSTEM dengan asesmen formatif. Oleh karena itu data peningkatan hasil pretest dan posttest digunakan untuk menunjukkan kemampuan literasi sains siswa setelah diberi perlakuan. Adapun hasil peningkatan kemampuan literasi sains siswa kelas eksperimen dan kelas kontrol dapat dilihat pada Tabel 3.

Tabel 3. Perbandingan Peningkatan Kemampuan Literasi Sains Siswa

\begin{tabular}{lccc}
\hline \multirow{2}{*}{ Kelas } & \multicolumn{2}{c}{ Rata-Rata } & \multirow{2}{*}{ Peningkatan } \\
\cline { 2 - 3 } & Sebelum & Sesudah & \\
\hline Eksperimen & 12,80 & 47,40 & 34,60 \\
\hline Kontrol & 25,91 & 48,44 & 22,53 \\
\hline
\end{tabular}

Pada Tabel 3, terlihat bahwa terdapat peningkatan hasil kemampuan literasi sains siswa pada kelas eksperimen dan kelas kontrol. Berdasarkan hasil analisis data dari uji hipotesis diperoleh $t_{\text {hitung }}>t_{\text {tabel }}=6,890>1,67$ dengan taraf signifikansi 0,05. Hasil hitung menunjukkan bahwa $\mathrm{H}_{0}$ ditolak dan $\mathrm{H}_{1}$ diterima. Dengan demikian, dapat disimpulkan bahwa siswa kelas XI MIA SMA Negeri 9 Malang pada pokok bahasan alat optik yang diberi perlakuan menggunakan model pembelajaran PjBL-STEM dengan asesmen formatif berbantuan UKBM berbasis PjBL-STEM memiliki peningkatan kemampuan literasi sains yang lebih tinggi dibandingkan dengan yang diberi perlakuan menggunakan model pembelajaran PjBL-STEM dengan asesmen formatif tanpa menggunakan UKBM berbasis PjBL-STEM. 


\section{PEMBAHASAN}

Hasil penelitian menunjukkan bahwa adanya peningkatan kemampuan literasi sains siswa kelas eksperimen dan kelas kontrol dengan menerapkan model pembelajaran PjBL-STEM dengan asesmen formatif. Hasil penelitian ini sesuai dengan penelitian yang dilakukan oleh Jauhariyyah, dkk. (2017) yang menjelaskan bahwa pembelajaran yang dilakukan dengan model pembelajaran PjBL-STEM dapat meningkatkan literasi sains.

Dalam pelaksanaan pembelajaran siswa kelas eksperimen dan kelas kontrol diberikan perlakuan dengan berbagai kegiatan yaitu menganalisis dan mencari solusi dari permasalahan, membuat dan uji coba proyek, mengolah hasil dari data uji coba proyek, dan mempresentasikan hasil proyek. Model pembelajaran berbasis proyek menekankan siswa belajar kontekstual melalui kegiatan-kegiatan kompleks seperti membuat proyek secara kolaboratif, bereksplorasi merencanakan aktivitas belajar, dan menghasilkan suatu produk. Siswa dilibatkan dalam pembelajaran berpendekatan sains, teknologi, teknik, dan matematika yang berbasis proyek untuk menyelesaikan permasalahan. Pelaksanaan pembelajaran ini sesuai dengan penelitian Han, dkk. (2015) bahwa dengan menerapkan model PjBL-STEM perlu melibatkan siswa dalam menerapkan berbagai cabang pengetahuan yaitu aspek sains, teknologi, teknik, dan matematika. Menurut (Mayasari et al., 2014) pembelajaran yang dilakukan dengan PjBL-STEM akan membuat Siswa memiliki literasi sains dan teknologi yang dapat dilihat dari membaca, mengamati, menulis, serta melakukan kegiatan sains sehingga dapat digunakan oleh Siswa untuk menyelesaikan permasalahan yang terjadi dalam kehidupan sehari-hari.

Pelaksanaan pembelajaran yang diberikan kepada kelas eksperimen yaitu dengan menerapkan UKBM berbasis PjBL-STEM dengan model pembelajaran PjBL-STEM dengan asesmen formatif, sedangkan untuk kelas kontrol diberikan perlakuan dengan model pembelajaran PjBL-STEM dengan asesmen formatif tanpa menggunakan UKBM berbasis PjBL-STEM. Hal ini sesuai dengan yang disampaikan oleh Pryor \&Kang (2013) bahwa pembelajaran dengan model PjBL-STEM yang dilakukan tidak hanya disertai dengan asesmen sumatif saja, akan tetapi juga disertai asesmen formatif mampu memberikan hasil yang lebih baik dibandingkan hanya menggunakan asesmen sumatif.

Penggunaan UKBM berbasis PjBL-STEM dalam proses pembelajaran siswa akan dibimbing dalam berlajar (Irwantha, dkk., 2017). Hal ini sesuai dengan peneitian yang dilakukan oleh Kertiasih, 2018 bahwa penggunaan UKBM dapat meningkatkan keterampilan imiah siswa. Megawati (2018) menyatakan bahwa untuk mengembangkan strategi pembelajaran di lingkup sekolah dengan tujuan agar tercapainya ketuntasan belajar, pendidik dapat menggunakan UKBM sebagai buku panduan mandiri yang dimiliki oleh siswa. Pertiwi, dkk (2018) menyatakan dalam penelitiannya bahwa proses pembelajaran saat ini berorientasi pada siswa kemudian untuk mencapai keberhasilan belajar dapat ditunjukkan dengan mengaplikasikannya dalam menyelesaikan suatu permasalahan yang nantinya akan meningkatkan litersi sains yang dimiliki siswa.

\section{KESIMPULAN}

Berdasarkan hasil analisis dan pembahasan, dapat disimpulkan bahwa siswa kelas XI MIA SMA Negeri 9 Malang pada pokok bahasan alat optik yang diberi perlakuan menggunakan model pembelajaran PjBL-STEM dengan asesmen formatif berbantuan UKBM berbasis PjBL-STEM memiliki peningkatan kemampuan literasi sains yang lebih tinggi dibandingkan dengan yang diberi perlakuan menggunakan model pembelajaran PjBL-STEM dengan asesmen formatif tanpa menggunakan UKBM berbasis PjBL-STEM. Oleh karena itu, dapat dikatakan bahwa model PjBL-STEM dengan asesmen formatif berbantuan UKBM berbasis PjBL-STEM berpengaruh pada kemampuan literasi siswa kelas XI IPA SMA Negeri 9 Malang pada pokok bahasan Alat Optik.

684 BRILIANT: Jurnal Riset dan Konseptual

Volume 5 Nomor 4, November 2020 


\section{SARAN}

Berdasarkan penelitian yang telah dilakukan, terdapat saran pada beberapa hal sebagai berikut.

1. Bagi Guru

a. Penggunaan UKBM dalam model PjBL-STEM dengan asesmen formatif berpengaruh pada peningkatan kemampuan literasi sains peserta didik, sehingga perlu untuk diterapkan dalam proses pembelajaran, akan tetapi guru harus memperhatikan dan menjelaskan model pembelajaran dan bahan ajar yang digunakan kepada peserta didik sehingga peserta didik mampu memahami tujuan dari pembelajaran yang akan dilakukan.

b. Penerapan UKBM dalam model PjBL-STEM dengan asesmen formatif pada pelaksanaannya dalam proses pembelajaran harus menekankan panduan yang ada pada UKBM, hal ini dikarenakan cakupan dalam UKBM sudah termasuk dalam model PjBL-STEM

2. Bagi Peneliti Lain

Berdasarkan hasil pembahasan, disarankan kepada peneliti lain untuk menyusun rencana pembelajaran dengan alokasi waktu yang tepat sehingga dalam pelaksanaan mengambil dan manganalisis data proyek dapat dilakukan dalam pembelajaran. Peneliti lain diharapkan mampu melakukan penelitian dengan menganalisis data yang lebih spesifik tentang domain literasi sains disetiap indikatornya. Selain itu peneliti lain diharapkan lebih menekankan kepada peserta didik untuk melihat panduan pada UKBM yang telah dirancang dengan model PjBL-STEM dengan asesmen formatif sebelum memberikan pembelajaran agar proses pembelajaran lebih mudah.

\section{DAFTAR RUJUKAN}

Afifah, T., Prasetyo, A. P. B., Lisdiana. 2016. Buku Guru dan Buku Siswa Terintegrasi Literasi Sains untuk Menumbuhkan Kesadaran Konsumsi Makanan Sehat. Journal of Innovative Science Education, 5(1), 36-44.

Asyhari, A., Hartati, R. 2015. Profil Peningkatan Kemamapuan Literasi Sains Siswa Melalui Pembelajaran Saintifik. Jurnal Ilmiah Pendidikan Fisika AlBiRuNi, 04(02), 179-191.

Elina, N., Prihandono, T., Wahyuni, S. 2017. Pengembangan Modul Alat-Alat Optik berbasis Pictorial Riddle pada Materi Pelajaran Fisika di Madrasah Aliyah. Seminar Nasional Pendidikan Fisika 2017, vol 2, 1-7.

Gherardini, M. (2016). Pengaruh Metode Pembelajaran dan Kemampuan Berpikir Kritis terhadap Kemampuan literasi Sains. Jurnal Pendidikan Dasar, 7(2), 253-264.

Han, dkk. 2014. How Science, Technology, Engineering, and Mathematics (STEM) Project Based Learning (PjBL) Affects High, Middle, and Low Achievers Differently: The Impact Of Student Factors On Achievement. International Journal of Science and Mathematics Education.

Hermawan \& Arief, Alimufti. 2014) Pengembangan Perangkat Pembelajaran Kurikulum 2013 Melalui Pendekatan Scientific Pada Materi Alat Optik untuk Melatihkan Sikap Ilmiah Siswa Kelas X SMAN 3 Surabaya. Jurnal Inovasi Pendidikan Fisika, 03(03),6-102.

Irwantha, M. D., Sriasih, S. A. P., \& Nurjaya, I. G. 2017. Penggunaan Unit Kegatan Belajar Mandiri Oleh Guru Dalam Pembelajaran Bahasa Indonesia 
Di Kelas X MIPA 2 SMA Negeri Bali Mandara. e-journal Jurusan Pendidikan Bahasa dan Satra Indonesia, 7(2)

Juhariyyah, F. R., Hadi Suwono, \& Ibrohim. 2017. Science, Technology, Engineering, and Mathematics Project Based Learning (STEM-PjBL) pada Pembelajaran Sains. In Pros. Seminar Pend IPA Pascasarjana UM, Vol. 2, 432-436

Kertiasih, L. E. (2018). Implementasi Pembelajaran Berbasis Inkuiri Wenning Berbantuan e-UKBM untuk Meningkatkan Keterampilan Ilmiah Siswa. Jurnal of Education Action Research, 2(4), 363-369.

Kurnia, F., \& Fathurohman, A. 2014. Analisis Bahan Ajar Fisika SMA Kelas XI di Kecamatan Indralaya Utara berdasarkan Kategori literasi Sains. Jurnal Inovasi Dan Pembelajaran Fisika, 1(1), 43-47.

Mayasari, T., Kadorahman, A., \& Rusdiana, D. 2014. Pengaruh pembelajaran terintegrasi science, technology, engineering, and mathematics (STEM) pada hasi belajar Siswa : Studi meta analisis, Prosiding Semnas Pensa VI "Peran Literasi Sains". Surabaya: UNESA

Megawati. 2018. Ragam Bahasa Siswa Sma Dalam Berbalas Pantun Dan Pengembangan Unit Kegiatan Belajar Mandiri (Ukbm) Sebagai Perangkat Ajar Untuk Memproduksi Teks Pantun Di SMA. Universitas Lampung.

National STEM Education Center. 2014. STEM Education Network Manual. Bangkok: The Institute for the Promotion of Teaching Science and Technology.

Nurjanah, A., Sudin, A., Sujana, A. 2017. Literasi Sains dalam Pembelajaran Berbasis Masalah (Penelitian Experimental terhadap Siswa Kelompok Atas, Tengah, dan Bawah SDN Warigin II dan SDN Palasah I di Kecamatan Palasah Kabupaten Majalengka pada Materi Energi Panas). Jurnal Pena Ilmiah, 2(1), 581-590

Pertiwi, U. D., Atanti, R. D., Ismawati, R. 2018. Pentingnya Literasi Sains pada Pembelajaran IPA SMP Abad 21. Indonesian Journal of Natural Science Education, 01(01), 24-29.

PISA. 2015. PISA 2015 Result in Focus. OECD Publishing

Pryor, C. R., \& Kang, Rui. 2013. Project Based Learning: An Interdisciplinary Approach For Integrating Social Studies With Stem Introduction. STEM Project Based Learning An Integrated Science, Technology, Engineering, And Mathematics (stem) Approach. Netherland: Sense Publisher.

Rachmawati, I. N., \& Gani, A. A. 2017. Implementasi Model Pembelajaran berbasis Proyek Project Based learning) dengan Analisis Kejadian Fisika dalam Pembelajaran Fisika di SMA. Jurnal Pembelajaran Fisika, 6(2), 189195.

Rahayuni, G. 2016. Hubungan Keterampilan Berpikir Kritis dan literasi Sains pada Pembelajaran IPA Terpadu dengan Model PBM dan STM. Jurnal Penelitian Dan Pembelajaran IPA, 2(2), 131-146. 